\title{
HEAT TRANSFER AND FLUID MECHANICS MEASUREMENTS IN TRANSITIONAL BOUNOARY LAYER FLOWS
}

\author{
T. Wang \\ Clenson University \\ Clemson, South Carolina 29631 \\ T.W. Simon \\ University of Minnesota \\ Minneapolis, Minnesota 55455
}

\author{
J. Buddhavarapu \\ TSI Inc. \\ St. Paul, Minnesota
}

\section{ABSTRACT}

Experimental results are presented to document hydrodynamic and thermal development of flat-plate boundary layers undergoing natural transition. Local heat transfer coefficients, skin friction coefficients, and profiles of velocity, temperature, and Reynolds normal and shear stresses are presented. A case with no transition and transitional cases with $0.68 \%$ and $2.0 \%$ free-stream disturbance intensities were investigated. The locations of transition are consistent with earlier data. A late-laminar state with significant levels of turbulence is documented. In late-transitional and early-turbulent flows, turbulent Prandt 1 number and conduction layer thickness values exceed, and the Reynolds analogy factor is less than, values previously measured in fully turbulent flows.

\section{NOMENCLATURE}

$c_{p}$

$\mathrm{C}_{\mathrm{f}} / 2 \quad$ Skin friction coefficient

Specific heat

Pr Prandt number

Pr $t \quad$ Turbulent Prandt 1 number

$\dot{q}^{\prime \prime} \quad$ Heat flux

$\operatorname{Re}_{x} \quad x$-Reynolds number

$\operatorname{Re}_{\delta *} \quad$ Displacement thickness Reynolds number

$\operatorname{Re}_{\theta} \quad$ Momentum thickness Reynolds number

St Stanton number

II Turbulence intensity

$\mathrm{I}^{+} \quad \frac{\left(\mathrm{T}_{w}-\mathrm{T}\right) \sqrt{\tau_{w} / \rho}}{\dot{q}^{\prime \prime} /\left(\rho c_{p}\right)}$

$\mathbf{u}, \mathbf{v}$

$u^{\prime}, v^{-}$

$\bar{u}$

$\mathrm{u}_{\tau}$

$\mathrm{u}^{+}$
Streamwise and cross-stream velocity

Streamwise and cross-stream velocity fluctuations

Streamwise mean velocity

Friction velocity $\left(\equiv \sqrt{\left.\tau_{w} / \rho\right)}\right.$

$\overline{\mathrm{u}} / \mathrm{u}_{\tau}$ $x$

y

$\mathrm{x}^{+}$

$\mathrm{Y}_{\mathrm{cl}}^{+}$

$z$

Greek

$p \quad$ Density

$T$ Shear stress

$\checkmark \quad$ Kinematic viscosity

$\delta_{99} \quad$ Boundary layer thickness based on $99 \%$ of

* the free-stream velocity

$\delta^{*} \quad$ Displacement thickness

$\Lambda_{\theta} \quad$ Momentum thickness $\quad \theta^{2} \mathrm{dU}_{\infty}$

Subscripts

$\begin{array}{ll}\frac{\text { at free strean }}{w} & \text { at wall }\end{array}$

\section{INTRODUCTION}

Transition from laminar to turbulent boundary layer flow effects significant increases in local wall shear stresses and convective heat transfer rates. These increases must be appropriately factored into the design of many types of equipment, e.g. compressor and gas turbine blades. Presently, the poor predictability of the location and streamwise coverage of transition on gas turbine blades results in either reduced longevity of the blade or reduced performance of the engine below design objectives. This inability to predict transition is partially due to a lack of experimental data, both heat transfer and hydrodynamic, which isolate the separate effects on transition. This, in turn, has retarded the endeavor to understand the transition process and to develop general prediction models. Some effects which are known to influence boundary layer transition are free-stream turbulence, acoustic disturbances, surface vibration, surface roughness, streamwise acceleration, cross-stream straining, film cooling injection, 
separation, compressibility effects, and streamwise curvature. Some characteristics of boundary layer transition which tend to exacerbate the difficulty in understanding the fundamentals are three-dimensionality; unsteadiness; interaction of several influences; and sensitivity to small influences which are not under the control of the experimenter or known to the designer. As much as $50-80 \%$ of a typical turbine blade surface is covered by flow undergoing transition (1). It is therefore important that a program of systematic, well-controlled experimental studies be initiated to provide the data base necessary for developing improved trans1tion prediction models.

The present experiment focuses on the effect of free-stream turbulence intensity and includes measurements of surface heat transfer rates as well as profiles of mean and turbulence quantities in the laminar, transitional, and turbulent flows. This test is the beginning of a series of tests which isolate the effects of free-stream turbulence intensity, streamwise acceleration, and streamwise curvature on transition. It is part of an ongoing series of experimental investigations on gas turbine heat transfer at the Heat Transfer Laboratory of the University of Minnesota.

As early as 1936. G. I. Taylor (2) analyzed freestream turbulence effects on transition for flow past a sphere. His work is believed to be the first where the effects of free-stream disturbances on transition were discussed. Early experiments of boundary layer transition on a flat plate were made by Hall and Hislop (3). Van Drfest and Blumer (4) developed an early prediction model by assuming that the breakdown of laminar flow occurs whenever the maximum of the local cross-span vorticity in the boundary layer becomes sufficiently distant from the wall. Their model, which accounts for free-stream turbulence and streamise acceleration effects, is still considered one of the better predictors of transition (5). Several constants in their model were determined from existing experimental data. Later, as more data became available, these constants were adjusted somewhat, e.g. (6). A forced-osctllation method for investigating boundary layer transition was Introduced by Schubauer and Skramstad (7) to demonstrate the growth and evolution of disturbances in laminar flows. They concluded that when the free-stream turbulence Intensity exceeds $0.1 \%$, transition is caused directly by random disturbances and is not precluded by selective amplification of sinusoidal oscillations (as with lower-disturbance flows). Klebanoff, Tidstrom, and Sargent (8) observed that, in low-disturbance flows, an initially two-dimensional wave, the growth of which is predictable by Ifnear theory of instablitty, develops three-dimensionalities--a feature of strong nonlinear development. The termination of this development is indicated by a sudden increase in the wave amplitude. Spangler and Wells (9) studied the importance of the frequency spectra and the origin of the disturbance (e. $g$. acoustic) on transition in low free-stream turbulence intensity flows $(<0.10 \%)$. They determined the disturbance intensity, versus disturbance frequency, required to initiate transition. A review of the understanding and prediction of transition, current to 1969 , was presented by Tani (10).

An empirical model for predicting the onset and end of transition was proposed by Hall and Gibbings (11). It Included the effects of free-stream turbulence and streamwise pressure gradient. Recently AbuGhannam and Shaw (12) developed an empirical relationship for the prediction of the start of transition, the end of transition and the development of momentum thickness, shape factor, intermittency factor, and skin friction coefficient during transition. The sole parameters in their model are the free-stream turbulence intensity and the free-stream acceleration.

In the gas turbine environment, free-stream turbulence intensities are in the range $5-20 \%$. To the authors' knowledge, few detalled transition studies have been conducted in such highly turbulent flows. Dyban, Epik, and Suprun (13) investigated the structure of laminar boundary layers developing under elevated free-stream turbulence intensities from $0.3 \%$ to $25.2 \%$. They found a peak in oscillation magnitude within the boundary layer, believed to be caused by the penetration of free-stream fluctuations. This peak amplitude reached a maximum in the $4.5 \%$ free-stream turbulence intensity case. The waveform of this oscillation was not sinusoidal but more turbulent-like with energy distributed across a wide range of frequencies. They cal1ed the late-laminar boundary layers which show this behavior "pseudo-laminar" to separate them fron the laminar and transitional boundary layers which are considered to be fundamentally different. The authors know of few other experiments where the turbulence (oscillation) developtent for natural transition through the laminar, "pseudo-laminar", transitional, and turbulent stages was documented $(14,15)$. More on transition can be found in Refs. (16-19).

The above studies are for isothermal flows. The following are studies of heat transfer in transitional flows: Junkhan and Serovy (20) conducted experiments on a constant-temperature flat plate to 1nvestigate the effect of free-stream turbulence intensity on heat transfer through transitional boundary layers. They found no effects of free-stream turbulence intensity within the laminar flow--only the well-documented effect on the location of transition. Simon and Moffat (21) measured heat transfer rates in a boundary layer which was undergoing transition on a convex-curved surface. They concluded that the onset of transition was delayed and that the evolution of transition was retarded by convex curvature. Recently, Blair (22, 23) conducted several tests on a unfformly heated flat wall where free-stream turbulence intensities were varied over the range $0.7 \%$ to $6.0 \%$. He concluded that fully turbulent mean velocity profiles were established faster than fully turbulent mean temperature profiles. Thts indicates a breakdown of the Reynolds analogy and a larger effective turbulent Prandt 1 number in the very early turbulent flow than in a mature turbulent flow. He also showed that the transition Reynolds number is insensitive to streamwise acceleration for $\Lambda_{0}<0.08$ over this turbulence intensity range. This is consistent with the van Driest and Blumer model.

In the present study, Reynolds streamwise-normal stresses were measured in addition to surface heat transfer coeffictents and mean velocity and temperature profiles to show the evolution of the turbulence structure inside laminar, transitional, and turbulent boundary layers during natural transition. Reynolds shear stresses were measured in the early-turbulent boundary layer. Two free-stream turbulence intensity levels, $0.68 \%$ and $2 \%$, were investigated. The streamwise pressure gradients in the three tests were small, and belleved to be inslgnificant, with $\Lambda_{\theta}<0.02$. Values in excess of 0.05 are needed to have a perceptible effect on the location of transition for these free-stream turbulence intensity values (4).

\section{EXPERIMENTAL FACILITY}

The test program employed the open-circuit, boundary layer heat transfer facility shown in Fig. 1 . Air is first drawn through $5 \mu \mathrm{m}$ filter material to a large centrifugal blower, then forced through a finned-tube heat exchanger and screen pack assembly to enter the test region. Free-stream nominal veloctities were 


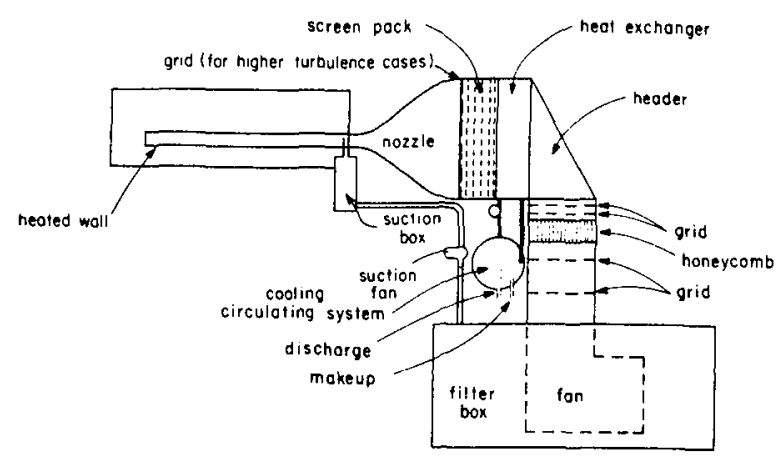

FIG. 1 PLAN VIEW OF TEST FACILITY

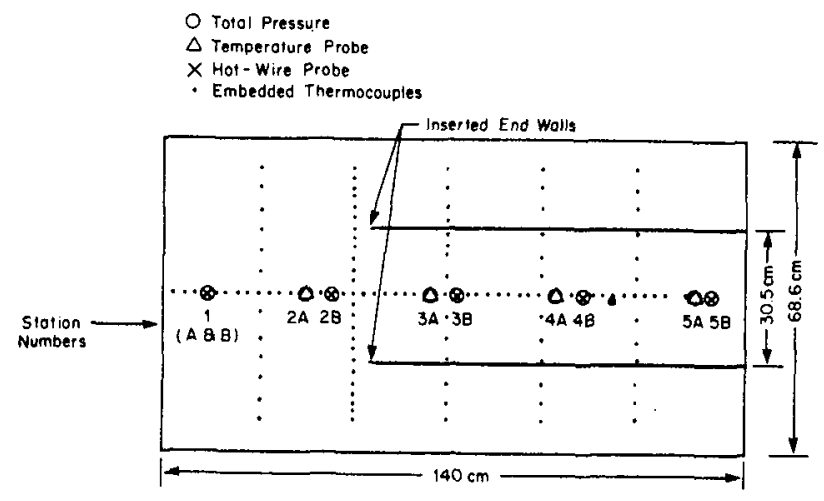

FIG. 2 MEASUREMENT LOCATIONS - HEATED BOUNDARY LAYER FLOW DATA TAKEN AT "A" STATIONS AND ISOTHERMAL FLOW DATA TAKEN AT "B" STATIONS

$12 \mathrm{~m} / \mathrm{s}$ and $35 \mathrm{~m} / \mathrm{s}$, uniform to $\pm 0.2 \%$ across the tunnel cross-section, for the present experiment, and the free-stream temperature was nominally $25^{\circ} \mathrm{C}$, uniform to $\pm 0.05^{\circ} \mathrm{C}$ and constant to within $\pm 0.2^{\circ} \mathrm{C}$. The room temperature, was held constant to within $\pm 0.5^{\circ} \mathrm{C}$. The test region is rectangular, $11.4 \mathrm{~cm} \times 68.6 \mathrm{~cm}(4.5$ inches $\times 27$ inches) in cross-section, and $1.4 \mathrm{~m}$ (55 inches) long. The test section was designed and constructed so that transition data with streamwise wall curvature could eventually be taken. For this straightwall study, it was necessary to insert end-walls beginning with sharp leading edges after $50 \mathrm{~cm}$ of the streamwise length and continuing throughout the remainder of the test region. These inserted end-walls reduced the effective span from $68.6 \mathrm{~cm}$ to $30.5 \mathrm{~cm}$ as shown in Fig. 2. One side wall of the tunnel, $68.6 \mathrm{~cm} \times 1.4 \mathrm{~m}$, was heated to nominally $10^{\circ} \mathrm{C}$ above the oncoming air temperature with a heat flux of $240 \mathrm{~W} / \mathrm{m}^{2}$, uniform to $\pm 1.0 \%$.

This is the heated, flat wall upon which data for the present study was taken. Strong suction was applied at the leading edge of this wall to remove the boundary layer which grows instde the nozzle. Therefore, the inltial flow on the test wall simulated the classical sharp-leading-edge configuration. The heated test wall is flexible so that transition studfes with

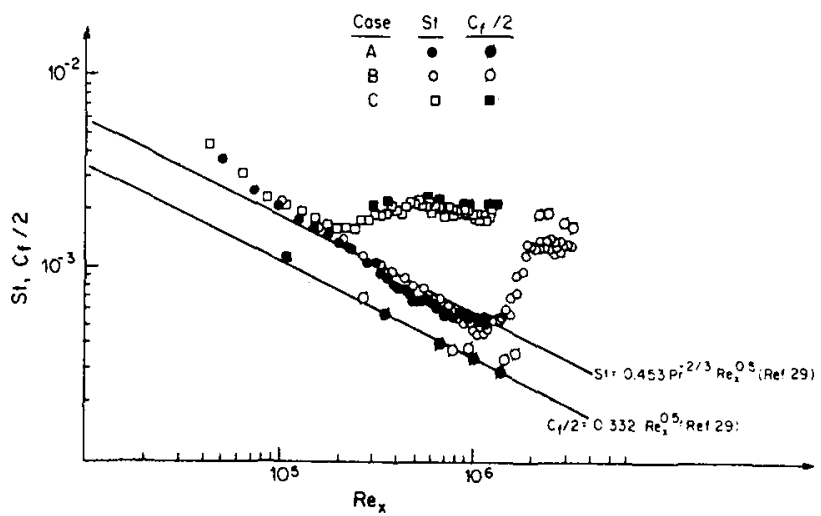

FIG. 3 STANTON NUMBERS AND SKIN FRICTION COEFFICIENTS VS, $x-R E Y N O L D S$ NUMBER

varying degrees of streamwise curvature could later be taken. The description of this heated wall follows. It begins with the surface adjacent to the room (the outside) and proceeds to the test surface (the inside). A $15.2 \mathrm{~cm}$ ( 6 inch) thick fiberglass insulation pad was installed on the outside of a $5 \mathrm{~mm}$ (3/16 inch) thick polycarbonate plastic (Lexan) support wall to minimize heat transfer to the room. Attached to the inside of the support wall is a 1 mm $(0.045$ inch) thick heating pad constructed of heater foll sandwiched between glass cloth and silicon rubber sheets. The foil provides Joule heating when energized with 60-cycle AC current using variable transformer voltage control. Bonded to the heater is a $0.25 \mathrm{~mm}$ (10 mil) thick rubber spacer within which $120,3-\mathrm{mil}$, chrome1-constantan thermocouple w1res were embedded. These thermocouples are distributed along the wall center-span, with a $2.54 \mathrm{~cm}$ (1 inch) spacing, and were uniformly distributed across the span at five streamwise locations (see Fig. 2). Covering the thermocouples, in contact with their junctions, and bonded to the spacer, is a $0.1 \mathrm{~mm}$ ( $4 \mathrm{mil}$ ) thick sheet of stainless steel. Bonded to the stainless steel and providing the test surface is a $0.025 \mathrm{~mm}$ ( $1 \mathrm{mll}$ ) thick sheet of reflective $\mathrm{f} 1 \mathrm{~lm}$. This $\mathrm{film}$, type $\mathrm{P}-19$ manufactured by the $3 \mathrm{M}$ Company, was added to reduce the uncertainty attributable to radiation exchange with the test wall.

The free-stream and boundary layer mean temperatures were measured with 3-mil thermocouples constructed of wire from the same manufacturing run as that of the embedded thermocouples. The thermocouples were calibrated in the tunnel against a calibrated, precision thermister known to be stable by continued comparison against a platinum resistance thermometer in the calibration laboratory. Mean velocity profiles were measured using $0.7 \mathrm{~mm}$ ( $28 \mathrm{mil}$ ) $0 . \mathrm{D}$. boundary layer total pressure tubes, $0.063 \mathrm{~mm}(2.5 \mathrm{mil})$ wall static ports, and $\mathrm{a} \pm 9 \mathrm{~cm} \mathrm{H} \mathrm{O}$ maximum pressure, reluctancetype, diaphragm differential pressure transducer (Validyne DP-45). Mean velocity measurements were taken in both heated and isothermal flows. Small variatlons in properties were included in the data reduction; the mean of the wall and free-stream temperature was used for property evaluation. Reynolds normal stresses were obtained in the isothermal flow with a horizontal hot-wire (TSI Model 1218, T1-5) maintained at a constant temperature. Reynolds shear stresses were taken in isothermal flows using a boundary layer $\mathrm{X}$-wire (TSI Model 1243, T 1.5) with constant-tempera- 
ture operation. The anemometer bridges were TSI Models 1050 and IFA-100. The pressure transducer and anemometer signals were digitized with an H-P Model 3437A, 3-1/2 digit voltmeter. Because only one digitizer was available, the shear stress measurements were taken one-wire-at-a-time. This is essentially the rotating slant-wire technique (24). Thermocouple EMF values were recorded with a Fluke Mode1 2205A multi-channel scanner. The total power supplied to the heater was computed as the product of a power factor, the measured voltage across the heater, and the current through the heater computed from the measured voltage across a precision resistor. The power factor, measured prior to the test, was within $0.1 \%$ of 1.0 . Data was reduced in a HP Series 200 Model 16 laboratory computer.

Corrections were made within the data reduction program for heat transfer through the fiberglass insulation, radiation exchange with the test wall, and streamwise conduction within the heated wall. A complete uncertainty analysis of the wall heat transfer data was also made within the data reduction program. This analysis employed the Kline and McClintack (25) methodology for computing the propagation of uncertainties and the Moffat (26) methodology for incorporating known contributors to bias error. Nominal values of wall heat flux uncertainty are presented along with other relevant uncertainties in Table 1. Detalls of the heater design, data reduction techniques, and wall heat flux uncertainty analysis can be found in Refs. $(27,28)$.

\section{EXPERIMENTAL RESULTS AND DISCUSSION}

The results of the following three cases are presented herein:

A. The Lamfnar Baseline Case (Turbulence Intensity, $\mathrm{TI}=0.3 \%$ ) - The laminar boundary layer extends over the entire test length. Transition correlations and the unsteadiness of the data indicate that transition is about to begin at the channel exit.

B. The Lower Free-Stream Turbulence Intensity Case (TI $=0.68 \%$ ) - The velocity is increased from that of Case $A$ and the onset of transition is moved to about one-third of the test length.

C. The Higher Free-Stream Turbulence Intensity Case (II $=2.0 \%$ ) - A coarse grid is inserted upstream of the nozzle and the free-stream velocity is reduced to move the onset of transition into the first onethird of the test length.

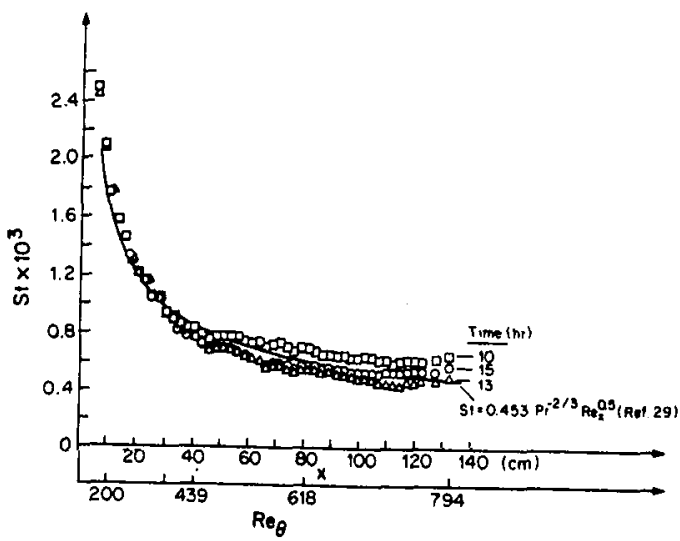

FIG. 4 LONG-PERIOD UNSTEADINESS OF STANTON NUMBER DATA FOR CASE A

\begin{tabular}{|c|c|c|}
\hline Variables & Range & Uncertainty \\
\hline $\begin{array}{l}\text { in the laminar \& } \\
\text { turbulent region }\end{array}$ & $0.2 \sim 5 . \times 10^{-3}$ & $\pm 2 \%$ \\
\hline $\begin{array}{c}\text { St in the transition } \\
\text { region }\end{array}$ & $0.2 \sim 2 . \times 10^{3}$ & $\pm 3 \%$ \\
\hline Mean Velocity & $0=35 \mathrm{~m} / \mathrm{s}$ & $\pm 2 \%$ \\
\hline Mean Temperature & $20 \sim 40 \mathrm{C}$ & $\pm 0.10 \mathrm{C}$ \\
\hline$\sqrt{\mathrm{u}^{2}} / \mathrm{U}_{\infty}$ & $0.1-11 \%$ & $\pm 5 \%$ \\
\hline$u^{\top} v^{\top} / v_{\tau}^{2}$ & $0 \sim 1$ & $\pm 10 \%$ \\
\hline $\mathrm{c}_{\mathrm{f}} \begin{array}{c}\text { (other than in } \\
\text { transition) }\end{array}$ & $0.2 \sim 2.0 \times 10^{-3}$ & $\pm 5 \%$ \\
\hline
\end{tabular}

TABLE 1 MEASUREMENT UNCERTAINTIES

\section{A. The Laminar Baseline Case - Case A}

The test facility was first qualified by conducting an all-laminar boundary layer test. A comparison of the results to laminar boundary layer theory (29), Fig. 3, shows that the Stanton numbers and skin friction coefficient values for this case follow the laminar correlation well, except at the very end of the test where it appears that transition is near. Stanton numbers for this and the subsequent cases were calculated directly from the measured (and corrected) wall heat flux and the measured local free-stream velocity, freestream temperature, and wall temperature. The wall temperature was taken as an average of five readings over a perfod of fifteen minutes. Skin friction coefficients were computed from the wall shear stress; which, in turn, is calculated from the local near-wall velocity gradient, $\tau_{\mathrm{w}}=\mu(\mathrm{du} / \mathrm{dy})$; and the local freestream velocity. One unanticipaled result in this experiment was the long-period unsteadiness shown in Fig. 4. Three sets of data were taken in one fifteenhour run. The first was taken after a ten-hour stabilization perfod as was also required for case $B$ and case $C$. As shown, the data fluctuated $\pm 10 \%$ about the laminar line. The mean data of the 5-hour data-taking period follow the laminar correlation well. The curve labeled "15-hour" is the data shown on Fig. 3. The theoretical stability limit for laminar boundary layer flow for a flat plate is $\operatorname{Re}_{\theta}=200$ (30) which, for this case, corresponds to $10 \mathrm{~cm}$ of development length and an $x$-Reynolds number of $0.97 \times 10^{5}$. Note that the Stanton number data remains repeatable for the first $30 \mathrm{~cm}\left(\operatorname{Re}_{\theta}=400\right)$ within the 5-hour data-taking period. The unsteadiness of this flow is presumed to be due to the sensitivity of this boundary layer to small disturbances to the flow in the face of a low free-stream turbulence intensity of $0.3 \%$. Possibilities would include the small variations in free-stream and wall temperatures (within the stated uncertainties) or small uncontrolled variations in tunnel vibration. Subsequent runs taken under these conditions over a period of one month showed that this long-period unsteadiness is repeatable. Long-period unsteadiness was not observable in cases $B$ and $C$ of this study, which have turbulence intensities of $0.68 \%$ and $2.0 \%$ respectively. Spanwise variations of Stanton number for five streamwise positions are shown on Fig. 5. At the first two positions, the heat transfer coeffictent is very spanwise-uniform; the stable laminar boundary layer is two-dimensional. Transition appears to begin as streaks off center-span. It symmetrically migrates toward the center-span. Transition is believed to be triggered in the three-dimensional corner flow region near the end-wall. It then is belleved to propagate by acoustic disturbance toward the center as discussed in Ref. (31). No spanwise data is shown for the region beyond the inserted end-walls (see Fig. 2). 


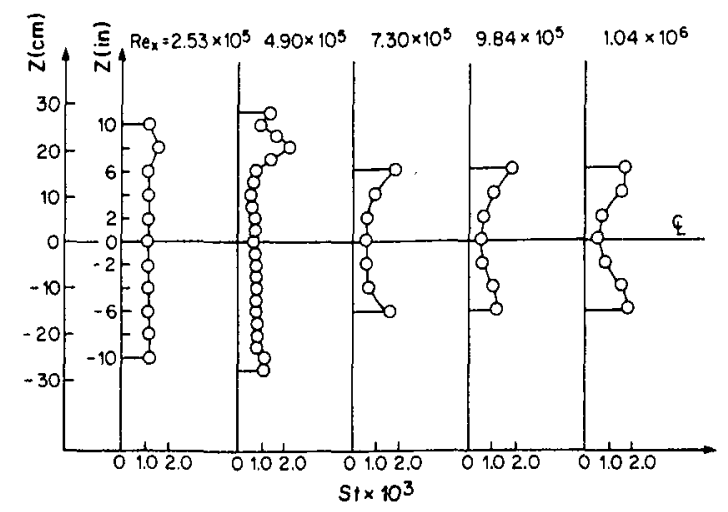

FIG. 5 SPANWISE DISTRIBUTIONS OF IOCAL STANTON NUMBER FOR CASE A (BASELINE CASE)

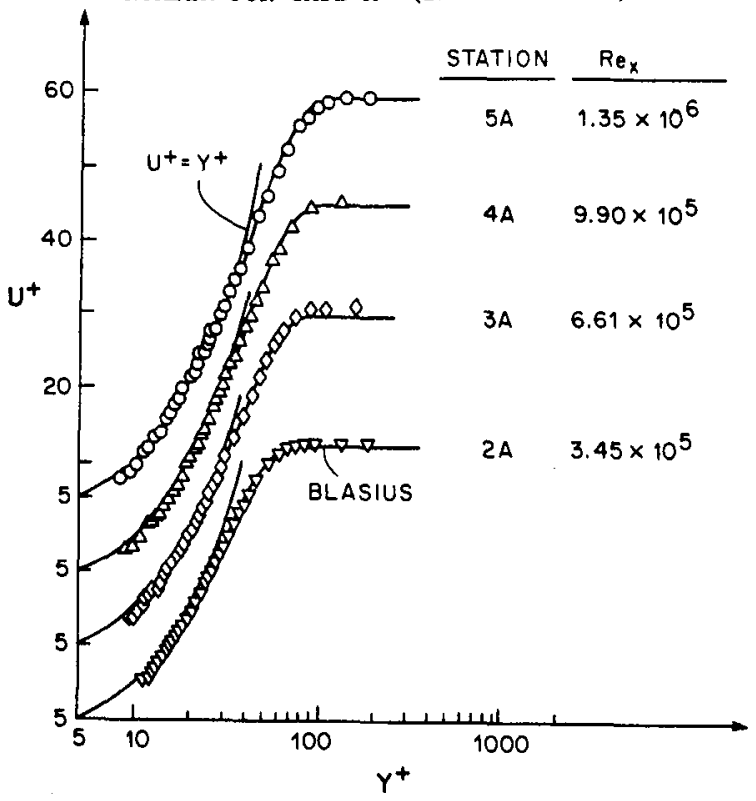

FIG. 6 MEAN VELOCITY PROFILES FOR CASE A

At the end of the test section, the momentum thickness Reynolds number is approximately 800 . According to the transition model of van Driest and Blumer (4), transition should begin about $\operatorname{Re}_{\theta}=890$ for a case having a free-stream turbulence intensity of $0.3 \%$; the flow is very near transition.

Mean velocity and mean temperature profiles plotted in inner coordinates, $\mathrm{U}^{+}$v.s. $\mathrm{Y}^{+}$and $\mathrm{T}^{+}$v.s. $\mathrm{Y}^{+}$, are shown on Figs. 6 and 7 , respectively. They appear to be typical laminar boundary layer profiles. Blasius velocity proftles are shown for comparison on Fig. 6. Mean velocity and temperature data were taken for this run and subsequent runs as time-averages over $30-40$ second periods.

A thermal energy balance applied over the entire test length using the time-average Stanton numbers on the centerline assuming two-dimensional flow achleved closure to within $3 \%$. This closure, the nearness of the Stanton number data to the laminar correlation, and the lack of premature transition in this case suggest that the facility is free of significant, uncontrolled disturbances and that the measurements are free of significant bias error. A momentum balance was also attempted; the lack of closure was $30 \%$.

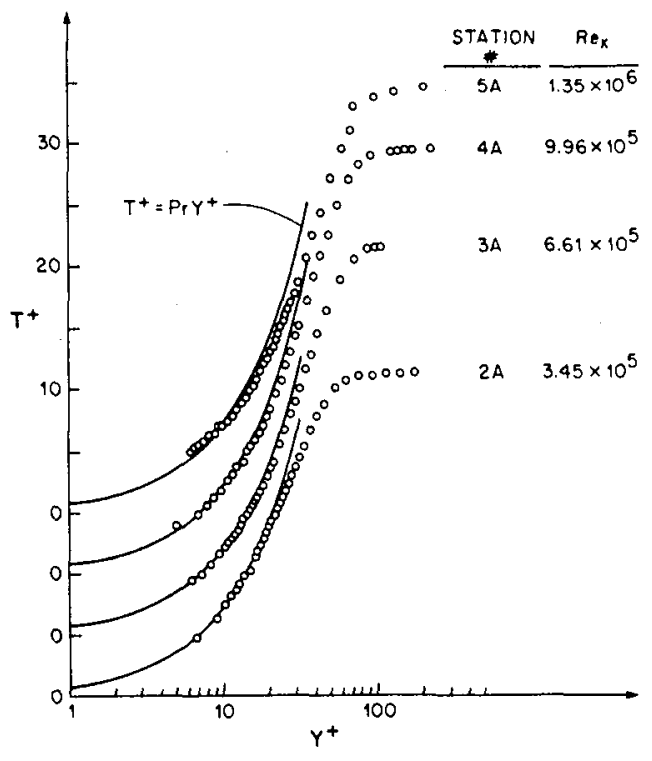

FIG. 7 MEAN TEMPERATURE PROFILES FOR CASE A

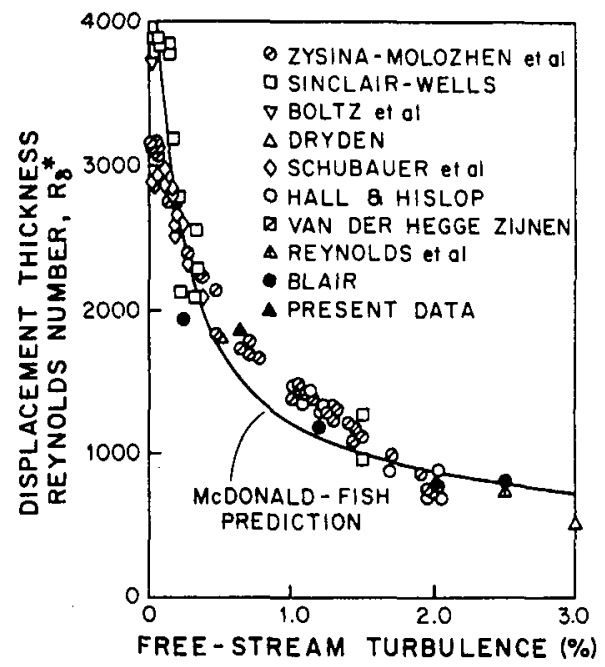

FIG. 8 EFFECT OF FREE-STREAM TURBULENCE ON TRANSITION REYNOLDS NUMBER FOR ZERO PRESSURE GRADIENT FLOW (FROM REF. 22)

This poor closure is believed to be due to the sparcity and inaccuracy of the skin friction coefficients deduced from velocity profiles, the inability to measure timeaverage skin friction coefficients (as was done with the Stanton number data for the energy balance), and the inability to measure momentum thicknesses with low uncertainty. Note that because of the sparce skin friction data, a momentum balance from only the first profile station to the last could be taken. This required taking prectse measurements of the momentum thickness in the very thin laminar boundary layer at the first station. Such a problem did not exist with the thermal energy balance which was taken from the leading edge to the last station. 


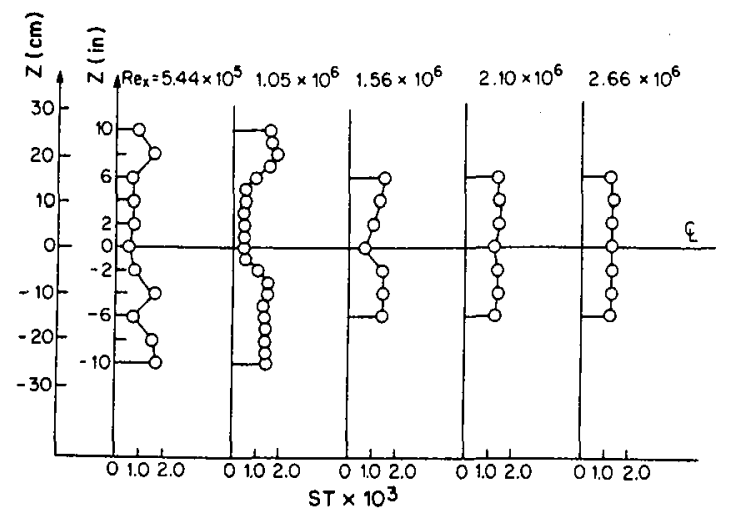

FIG. 9 SPANWISE DISTRIBUTION OF LOCAL STANTON NUMBER FOR CASE B

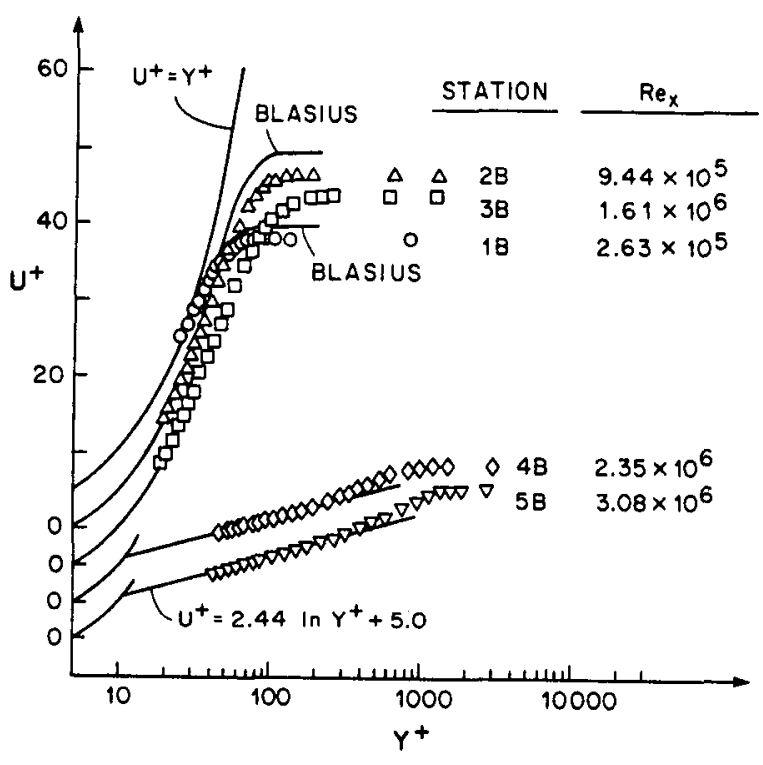

FIG. 10 MEAN VELOCITY PROFILES FOR CASE B

B. The Lower Free-Stream Turbulence Intensity Case Case B

In the second case, the free-stream velocity was increased to nominally $35 \mathrm{~m} / \mathrm{s}$ which moved the location of the beginning of transition to about one-third of the test length. The resulting free-stream turbulence intensity became $0.68 \%$. Stanton number and skin friction coefficlent data for this case are shown on Fig. 3 . Transition, taken to be the beginning of the dramatic increase in heat transfer coefficient and shear stress, is shown to be at an x-Reynolds number of about $1.2 \times 10^{6}$. At this location the displacement thickness Reynolds number is 1890 . Transition at this location is consistent with the van Driest and Blumer (4) model or the McDonald and Fish (32) model (shown on Fig. 8). The skin friction coefficient and Stanton number data follow the laminar correlation well. No significant change in the laminar data due to the increase in free-stream turbulence from that of case $A$ is observable. Stanton number values have been previously shown to exceed $\mathrm{C}_{f} / 2$ values in a mature turbulent boundary layer
$(33,34)$. Spalding (33) showed that the value of the "Reynolds Analogy Factor", $2 \mathrm{st} / \mathrm{C}_{\mathrm{f}}$, for air is 1.2. The Reynolds analogy factor for the early-turbulent region of case $B$ is about 0.75 , however. This indicates a slower response of the heat transfer data in transition than that of the hydrodynamic data, as was observed by Blair (22). It will subsequently be shown that the turbulent Prandt1 number in the low-Reynolds-number turbulent flow for case $B$ is considerably larger than 0.9 , the value measured for mature turbulent boundary layers. Skin friction values for the laminar flow were calculated as discussed previously in case $A$. Two $C_{f} / 2$ values, $R_{x}=1.4 \times 10^{6}$ and $1.6 \times 10^{6}$ (Fig. 3), were calculated ${ }^{x}$ assuming a laminar boundary layer though the profiles clearly indicate a beginning of transition (as will be discussed). The values shown, therefore, represent lower-bound values. $C_{f} / 2$ values for turbulent flows were deduced from the law-of-the wall using the Clauser technique (35). No direct measurements of wall shear stress were made.

Spanwise distributions of local Stanton number are shown on Fig. 9. At the first station, the boundary layer momentum thickness Reynolds number, 300 , exceeded the stability limit of $\operatorname{Re}_{\theta}=200$, and is clearly showing signs of transition. These are observable as streaks of high local heat transfer coefficient off the center-span. Downstream, these regions of early transition grow to effect transition on the centerline. A notable difference from the profiles shown for case $A$ is the lack of symmetry. Transition at the center-span location is underway by the second profile and is complete by the fourth (Figs. 3 and 9). At the last station, effective turbulent cross-stream transport has restored two-dimensionality.

The local heat transfer data for this run were repeatable to within $1 \%$ over a six-hour test period, beginning after the standard ten-hour equilibrium period. In a similar case they were repeatable to within $3 \%$ over a period of one month.

Mean velocity profiles are shown in Fig. 10. The two upstream profiles (Stations $1 \& 2 B$ ) follow the $\mathrm{U}^{+}=\mathrm{Y}^{+}$correlation to $\mathrm{Y}^{+}=20$, indicating laminar-like behavior even though there are signs of the beginning of transition at these locations as discussed above. The two downstream profiles (Stations 4B \& 5B) follow the law-of-the wall relationship over a sufficient range of $\mathrm{Y}^{+}$that using the Clauser technique was deemed appropriate. The third profile (Station 3B), though reduced with a skin friction coefficient calculated from the near-wall velocity gradient, as done with the laminar profiles, is clearly not laminar-like. This profile also does not display the turbulent log-linear behavior with an appropriate cholce of $C_{f} / 2--1 t$ is clearly transitional. One method for finding the transition region $\mathrm{C}_{\mathrm{f}} / 2$ is to force closure of the two-dimensional momentum integral equation through the transition region (22). This method was trled and found to give values which appear unreasonably high for this case. This is believed to be attributable to the influence of the lack of twodimensionality in the transition region for this low free-stream turbulence case.

Mean temperature profiles are shown on Fig. 11. The first profile (Station 2A), taken in the laminarlike flow, follows the near-wall correlation, $\mathrm{T}^{+}=$PrY $\mathrm{Y}^{+}$, well. The two downstream profiles (Stations $4 \mathrm{~A}$ and $5 \mathrm{~A})$, taken in the turbulent flow, display therma1-log-law behavior. In fitting the log regions, the turbulent Prandt1 number, $\mathrm{Pr}$, and the conduction layer thickness, $\mathrm{Y}^{+}$, were considered free parameters. Bestfits were found with $\mathrm{Y}^{+}=20$ and $\mathrm{Pr}_{t}=1.20$ and 1.15 for Re $=2.1 \times 10^{6}$ and $2.9 \times 10^{6}$, respectively. These values of $\mathrm{Pr}_{t}$ are consistent with the trend in $2 \mathrm{st} / \mathrm{C}_{\mathrm{f}}$ 


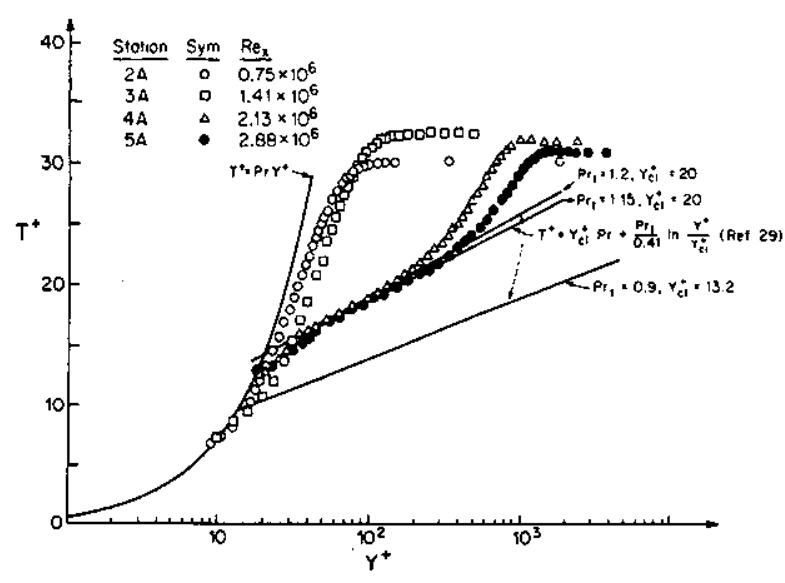

FIG. 11 MEAN TEMPERATURE PROFILES FOR CASE B

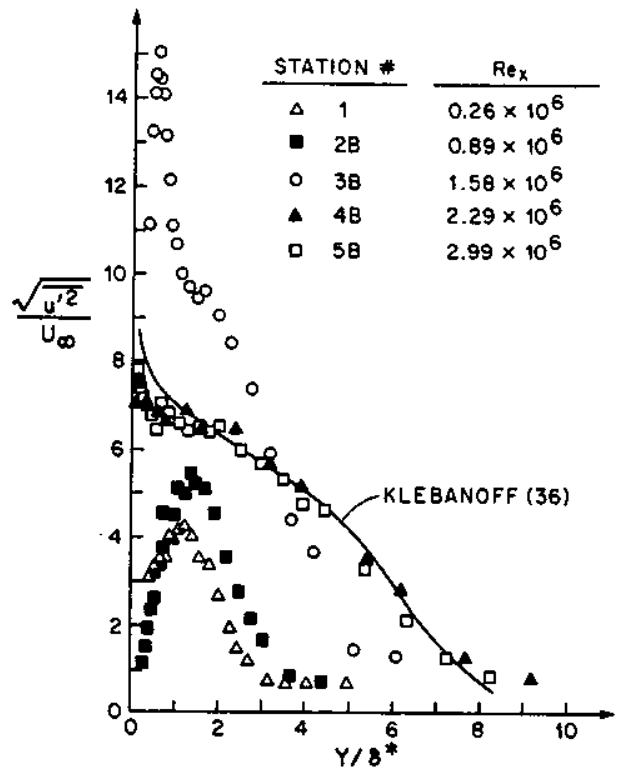

FIG. 12 REYNOLDS STREAMWISE-NORMAL STRESS PROFILES FOR CASE B

observed in FIg. 3 and the conclusion, also made by Blatr (22), that Reynolds analogy is violated in the low-Reynolds number turbulent boundary layer. Figure 11 also shows that the conduction layer thickness is larger in the low-Reynolds-number turbulent flow than that observed in higher Reynolds number flows (29).

Profiles of Reynolds normal stresses, $\sqrt{u^{-2}} / U_{\infty}$, are shown in Fig. 12. The two upstream profiles (Stations $1 B \& 2 B$ ) have some turbulence-like characteristics although the mean velocity and temperature profiles and the Stanton numbers at this streamwise position appear laminar-like. The anemometer output signals were viewed on a storage oscilloscope. At the peak value, 1.e. $y / \delta^{*}=1.3$ for the first station, the waveform was turbulent-like indicating a distribution of energy over a large range of frequencies. No intermittent non-turbulent behavior was observable. At the innermost $y$-position of station 1 data ( $R e=2.63 \times 10^{5}$, $\left.\mathrm{y} ! \delta^{*}=0.3\right)$, some intermittency was observed where a quiet signal was present about $5 \%$ of the time. These findings are consistent with the results of Dyban (13) et. al. They termed such a boundary layer "pseudo- laminar". It is believed that this turbulence is produced by non-linear amplification of the free-stream disturbances. This process gives rise to streamwise vortices which concentrate in a thin layex termed that "shear layer" by Klebanoff et. al. (8). This "shear layer" is characterized by high-frequency disturbances and turbulence intensities similar to the peaks of streatuwise turbulence intensity shown in Fig. 12. The near-wall decay of turbulence intensity is presumed to be due to stabilizing viscous forces. The effect of these turbulent-like fluctuations on the transition process is presently unknowm. Schubauer and Skramstad (7) observed weak oscillations preceding transition in a flow where disturbances were very small. Klebanoff, Tfdstrom, and Sargent (8) observed that, in a laminar boundary layer disturbed by a vibrating ribbon, an initially two-dimensional wave develops into a threedimensional pattern which is terminated by a sudden increase of wave amplitude. Profiles of rms values of these waves are similar (including a peak at $y / \delta^{*}=1.3$ ) to those profiles of Fig. 12, which precede transition. Transition is observable in the normal stress profiles as a very large increase in peak turbulence intensity concentrated near the wall where 1 t is believed that turbulent bursts are agitating the flow (Station 3B profile of Fig. 12). The residue of the laminar profile peaks remain in the downstream profiles but soon becomes overshadowed by the intense near-wall peak (Stations $4 B \& 5 B)$. The outer half of the transitional boundary layer profile (Station $3 B$ ) has a low turbulence intensity compared to fully-turbulent profiles (i.e., Stations 4B \& $5 B)$. Though the two downstream stations ( $4 B$ and $5 B$ ) are in a low-Reynolds-number turbulent flow, they appear to have reached an equilibrium shape. This is evidence that the turbulence characteristics are established almost immediately after transition. The last two profiles appear similar to one measured in a mature turbulent boundary layer by Klebanoff (36). Note that the Station $3 B$ profile is different than efther the laminar or turbulent profile and therefore cannot be reproduced from the two by way of an intermittency factor, as is often done in transitional flow modeling.

Reynolds shear stress profiles for the two downstream stations are shown on FIg. 13 (37). The probe was too large to take similar profiles in the laminar and transitional boundary layers. This data and the Klebanoff (36) data, also shown, support the earlier conclusion that the turbulence characteristics rapidly assume those of a fully-turbulent flow. The reduced

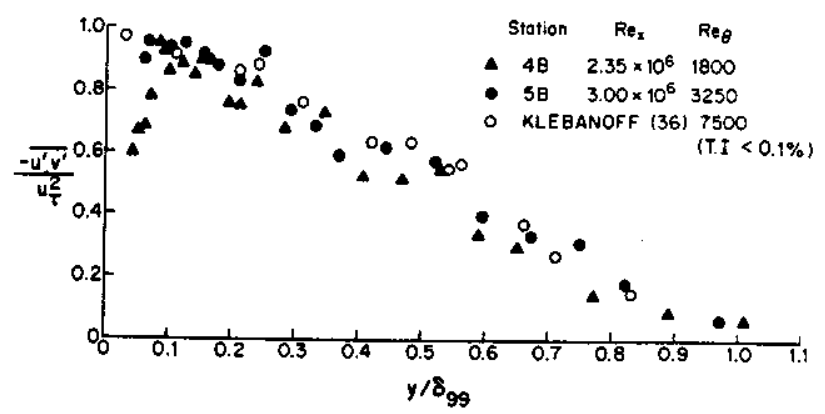

FIG. 13 REYNOLDS SHEAR STRESS PROFILES FOR CASE B 


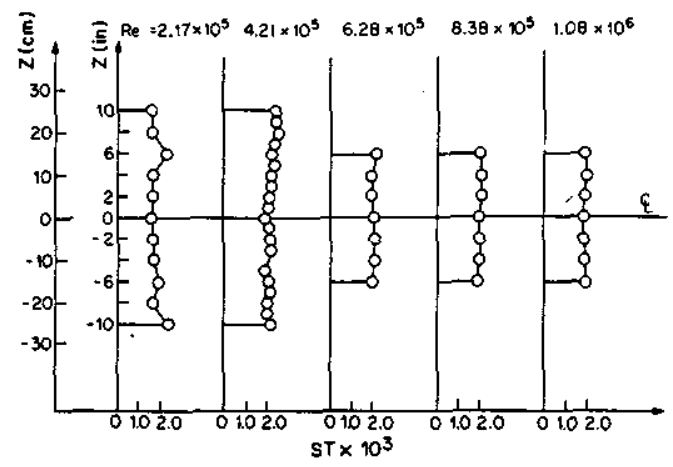

FIG. 14 SPANWISE DISTRIBUTIONS OF LOCAL STANTON NUMBER FOR CASE C

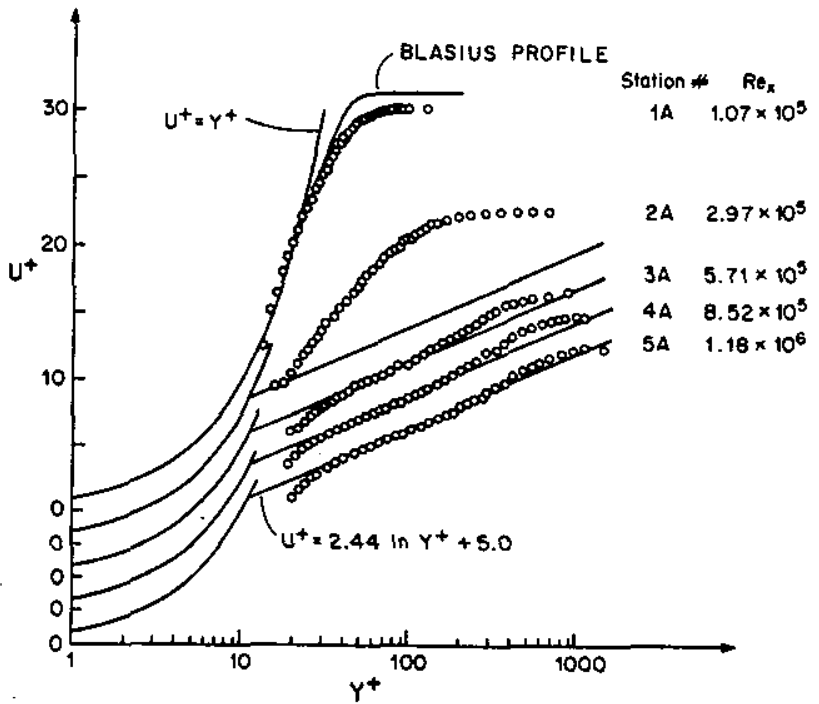

FIG. 15 MEAN VELOCITY PROFILES FOR CASE C

shear-stress values near the wall in the Re * $2.35 \times 10^{6}$ profile are probably due to averaging by the probe over the length of the wire. This was not observable in the last station profile where the boundary layer was considerably thicker.

c. The Higher Free-Stream Turbulence Intensity Case Case C

To set up the third case, a square grid constructed of $5 \mathrm{~cm}$ wide metal strips on a $10 \mathrm{~cm}$ pitch, was inserted between the screen pack and the nozzle. The free-streatn velocity was then reduced to approximately $13 \mathrm{~m} / \mathrm{s}$ to place the onset of transition onto the first one-third of the test length. This gave free-stream turbulence intensities which decay from $2.1 \%$ to $1.9 \%$ over the test length; $2.0 \%$ was recorded in the transition region. Larger values of free-stream turbulence intensity, though more representative of the gas turbine environment, decay rapidly and are difficult to characterize and reproduce. This case is considered representative of cases with higher free-stream disturbance (TI $<5 \%)^{+}$

The Stanton number and skin friction coefficient data, Fig. 3, show that the onset of transition has been moved to approximately $R e_{\mathrm{X}}=2.1 \times 10^{5}$ (Re $\left.\delta_{*}=788\right)$. This is consistent with eârlier data shown on Fig. 8 for $2 \%$ free-stream turbulence intensity. There also is some indication of a higher heat transfer coefficient in the late laminar flow due to the higher free-stream turbulence intensity although the data for $R e<10^{5}$ seems to be insensitive to turbulence intensity. The two skin friction coefficient values at $\operatorname{Re}_{*} \approx 3 \times 10^{5}$ were found by forcing closure of the integraf momentum equation over the transition region as previously done by Blair (22). In contrast to case $B$ this technique was found to give values that appear reasonable on Fig. 3. It is believed that this model was successful in case $C$ and not in case $B$ because case $C$ was shown to be more two-dimenslonal. The data indicate that the $x$-Reynolds number at the end of transition is about twice that of the onset of transition for both cases $B$ and $C$. This is consistent with the transition length model presented by Abu-Ghannan and Shaw (12). The turbulent data

$\left(\mathrm{Re} \times 4 \times 10^{5}\right)$ indicate a lower value of $2 \mathrm{st} / \mathrm{C}_{\mathrm{f}}$ than $1.2^{x}$, the accepted value for fully-mature turbulent flow $(33,34)$, but a higher value than observed in case $B$. Also, it will be shown that turbulent Prandt1 numbers are reduced somewhat from those of case B. A thermal energy balance ylelded closure to within $5 \%$ over the full test length for this case and a momentum balance, closed to within $4 \%$ from the first profile ( $\operatorname{Re} \approx 10^{5}$ ) to the last $\left(\operatorname{Re} \approx 1.3 \times 10^{6}\right)$. It should be nôted, however, that the two $C / 2$ values within the transition region ( $\mathrm{Re}_{\mathrm{X}} \approx 3.5 \times 10^{5}$ ) were chosen to force momentum balance cloxsure over the transition region, $2.1 \times 10^{5}<\operatorname{Re}<5 \times 10^{5}$.

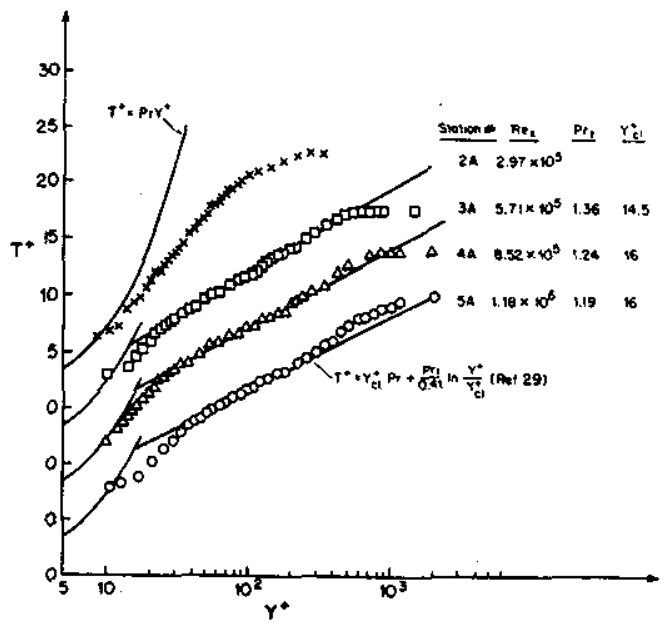

FIG. 16 MEAN TEMPERATURE PROFILES FOR CASE C

7 The upper 1imit of $5 \%$ was imposed based upon the findIngs of Dyban et. al. (13) that the characteristics of "pseudo-Iaminar" flows for TI > 5\% are different than those for TI $<5 \%$. 


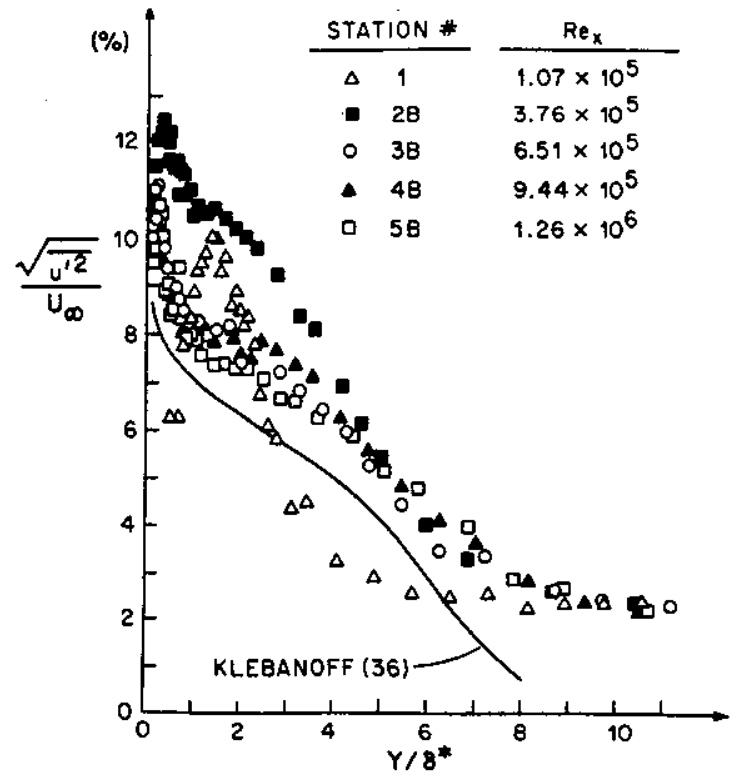

FIG. 17 REYNOLDS STREAMWISE-NORMYL STRESS PROFILES FOR CASE

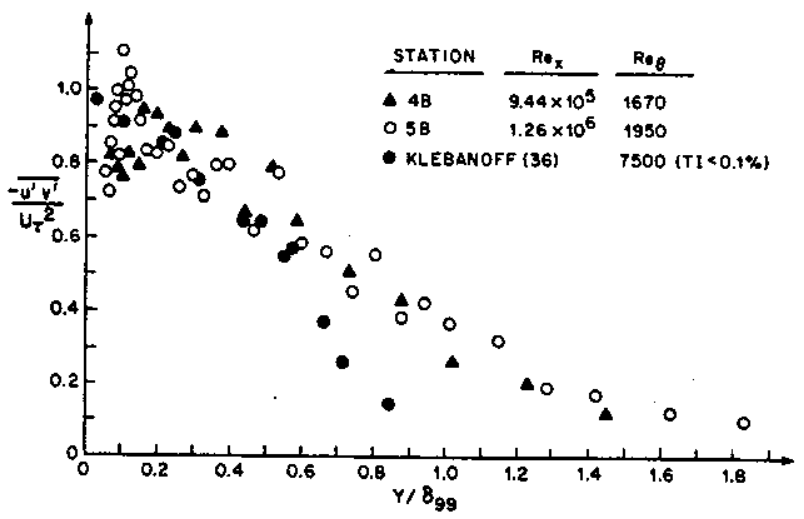

FIG. 18 REYNOLDS SHEAR STRESS PROFILES FOR CASE C

Spanwise distributions of Stanton number are shown in $\mathrm{Fig}_{\mathrm{g}}$ 14. The first distribution is in late-laminar flow. Transitional streaks are beginning to form off center-span as was observed in case $B$. The second $\mathrm{d} 1 \mathrm{~s}-$ tribution is in late-transitional flow. It appears that transition near the center-span is spanwise-unif orm and that the flow remains two-dimensional throughout, for this high turbulence case.

Mean velocity profiles, Fig. 15, show behavior similar to that of case $B$. The upstream station (Station 1) is laminar-like, the next (Station 2B) is in transition and the three downstream stations (3A, 4A and 5A) are clearly turbulent - each with a longer loglinear region and a decreased wake strength than the last. A comparison of the Station 1 profile with the Blaslus profile (Fig. 15) shows a lack of agreement at the edge of the boundary layer. This may be due to the nearness of the flow to transiton (Fig. 3) or due to the higher free-stream turbulence level of Case $C$. Mean temperature profiles of case C, F1g. 16, show behavior similar to that of the case $C$ velocity profiles. Note that the upstream profile (Station 2A) is in transtition. The turbulent profiles (Stations $3 \mathrm{~A}$, 4A and 5A) show log-linear behavior. As in case $B$, the $\log$ regions were $f 1 t$ by assuming the turbulent Prandt 1 number, $\mathrm{Pr}_{t}$, and the conduction layer thickness, $\mathrm{Y}_{\mathrm{C} i}^{+}$, to be freetparameters. Best fits were achieved with $\mathrm{Y}^{+}=14.5,16$ and 16 , and $\operatorname{Pr}_{+}=1.36,1.24$ and 1.19 for stations $3 \mathrm{~A}, 4 \mathrm{~A}$ and $5 \mathrm{~A}$, respectively. Note that the conduction layers for the last two profiles are thinner than those of case $B$, but thicker than those of a mature turbulent boundary layer $\left(\mathrm{Y}^{+}{ }^{+}=13.2\right.$ (29)). Note also that the turbulent Prandt number are higher than 0.9 , the fully turbulent value, and less than those observed just after transition in case $B$. Reynolds normal stress profiles, plotted in Fig. 17, continue to show a peak at $y / \delta^{*}=1.3$ in the laminar flow (Station 1) as was observed in case $B$. The peaks and values throughout the profile are larger than the case $B$ counterparts, however. The residue of the peak in the laminar profiles remains in the downstream profiles but soon becomes overshadowed by the near-wall peak. The three downstream profiles (3B, 4B and 5B) are nearly the same, supporting the earlier conclusion that the turbulence quantities are rapidly established. Due to the higher free-stream turbulence, the values throughout the profile are higher than the case $B$ values and those of Klebanoff (36), however.

Reynolds shear stress profiles are shown on Fig. 18. Though the scatter is large, the figure shows that the downstream profiles (Stations 4B and 5B) are essentially the same. Fig. 18 also shows that the near-wall shear stress is approximately the same, in these coordinates, as that in the Klebanoff profile (36). The shear stress near the edge of the boundary layer is considerably larger than Klebanoff's values, however -- the freestream turbulence for the Klebanoff data was very low (TI $<0.1 \%$ ). Figure 19 compares the shear stress profiles from the last station for cases B and C. A1though the near-wall values are essentially the same in these coordinates, the case $C$ values near the edge of the boundary layer are considerably higher.

\section{CONCLUSIONS AND RECOMMENDATIONS}

1. An unstable laminar flow is described as a separate flow fron that of laminar or transitional flow. In this flow, turbulence intensities significantly higher than the free-stream turbulence intensity are observable in the boundary layer. Heat transfer rates appear to be somewhat sensitive to free-

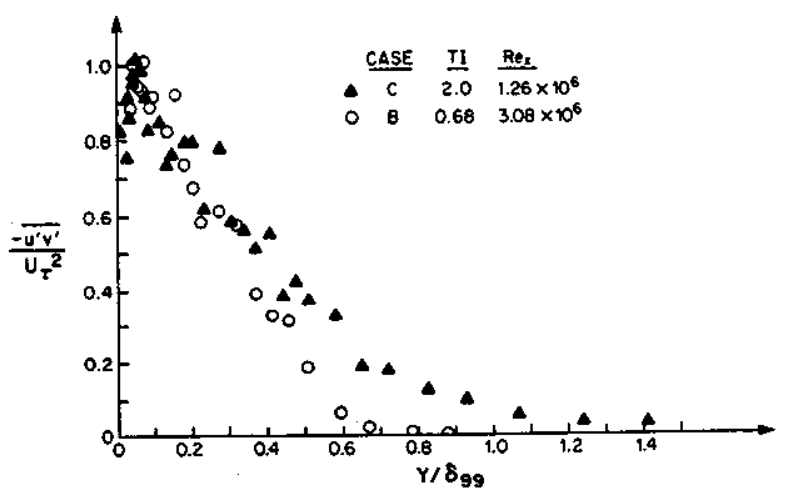

FIG. 19 COMPARISON OF REYNOLDS SHEAR STRESS PROFILES AT STATION 5B (FIG. 2) FOR CASES B AND C 
stream turbulence in this flow -- a contrast to the lack of sensitivity to free-stream turbulence intensity in the early laminar flow. Hore investigation into the role of this boundary layer turbulence intensity on the process of transition is needed.

2. Increased free-stream turbulence intensity decreases the transition onset Reynolds number and the length of transition. The locations of the onset and end of transition in the present cases were consistent with results of earlier experiments. Onset of transition is taken to be the location where Stanton number data begin to rise sharply with increasing streamwise distance; the end of transition is the peak of the Stanton number curve.

3. Turbulent Prandtl number values in the early turbulent flow, fust downstream of transition, are significantly higher than the 0.9 value known to apply to fully-mature turbulent flows. These values decrease, somewhat, with higher free-stream disturbance levels. Temperature profiles in the early turbulent flow Indicate a thicker conduction layer than observed in fully-turbulent flows. This thicknesss decreases with increased free-stream disturbance levels.

4. Values of the Reynolds analogy factor, $2 \mathrm{St} / \mathrm{C}_{\mathrm{f}}$, in the early turbulent flow are significantly smaller than 1.2 , the fully-turbulent value.

5. Profiles of turbulent streamwise-normal and shear stresses develop rapidly to fully-turbulent shapes fmediately after transition.

6. Transition is characterized by a very large spike in streamwise turbulence intensity near the wall. This spike is considerably larger than the maximum value observed in turbulent normal stress profiles.

7. The effect of higher free-stream turbulence intensity is seen to penetrate to very near the wall in profiles of streamwise-normal stresses. The effect of higher free-stream disturbance on the shear stress profiles in the fully turbulent flow is seen predominately in the outer portion of the boundary layer.

8. Long-period unsteadiness was observed in a low freestream-disturbance (TI $=0.3 \%$ ) laminar flow downstreat of the theoretical instability 1imit. Similär unsteadiness was not observed fust before transition in higher-disturbance flows (TI $=0.68 \%$ and $2 \%$ ).

\section{ACKNOWLEDGMENTS}

This study was supported by the NASA-Lewis Research Center grant number NAG 3-286. The grant monitor is Dr. Raymond Gaugler. Additional support was provided by the Graduate School of the University of Minnesota.

\section{REFERENCES}

1. Turner, A. B., "Local Heat Transfer Measurements on a Gas Turbine Blade," J. of Mech. Engr. Sc1, Vol. 13, No. 1,1971, pp. 1-12.

2. Taylor, G. I., "Statistical Theory of Turbulence, Part V", Proc. Roy. Soc. (London) A156, 1936, pp. 307-317.

3. Hail, A. and Hislop, G. S., "Experiments on the Transition of the Laminar Boundary Layer on a Flat Plate," British Aeronautical Research Comnittee, $R \& M 1843,1938$.

4. van Drlest, E. R. and Blumer, C. B., "Boundary Layer Transition: Free-stream Turbulence and Pressure Gradient Effects," AIAA J., Vol. 1, No. 6, June 1963, Pp. 1303-1306.
5. Hylton, L. D., Mihelc, M. S., Turner, E. R., Nealy, D. A., and York, R. E., "Analytica? and Experimental Evaluation of the Heat Transfer Distribution Over the Surfaces of Turbine Vanes," NASA CR168015, May 1983.

6. Wells, C. S., Jr., "Effects of Freestream Turbulence on Boundary Layer Transition," AIAA J., Vol. 5, No. 1, 1967, pp. 172-174.

7. Schubauer, G. B. and Skramstad, H. K., "Laminar Boundary Layer Oscillations on a Flat Plate," NACA Report, No. 909, 1948.

8. Klebanoff, P. S., Tidstrom, K. D., and Sargent, L. H., "The Three-Dimensional Nature of Boundary Layer Instability," J. Fluid Mech., 12, Part I, 1962, Pp. 1-34.

9. Spangler, J. G. and Wells, C. S., Jr. "Effects of Freestream Disturbances on Boundary Laver Transition," AIAA J., Vol. 6, No. 3, 1968, pp. 543-545.

10. Tani, I., "Boundary Layer Transition," Annual Rev. of Fluid Mech., Vo1. I, 1969, W. R. Sears, Editor, Pp. 169-196.

11. HaI1, D. J, and Gibbings, J. C., "Influence of Stream Turbulence and Pressure Gradient Upon Boundary Layer Transition," J. of Mech. Engr. Dtiv. Vol. 14, No. 2, 1972, pp. 134-146.

12. Abu-Ghannam, B. J., and Shaw, R., "Natural Transition of Boundary Layers -- The Effects of Turbulence, Pressure Gradient, and Flow History," $\mathrm{J}$. of Mech. Engr. Sc1., Vo1. 22, No. 5, 1980, pp. 213-228.

13. Dyban, YE. P., Eplk, E. YA., and Suprun, T. T., "Characteristics of the Laminar Boundary Layer in the Presence of Elevated Free-Stream Turbulence," Fluld Mech.-Soviet Research, Vol. 5, No. 4, 1976 , pp. 31-36.

14. Clauser, M. and Clauser, F., "The Effect of Curvature on the Transition from Laminar to Turbulent Boundary Layer," NACA Tech. Note No. 613, 1937.

15. Liepmann, H. W., "Investigations on Laminar Boundary-Layer Stability and Transition on Curved Boundaries, NASA Wartime Advanced Confidential Rept. 3H3D, Aug, 1943.

16. Morkoven, M. N., "Instability, Transition to Turbulence and Predictability, AGARDograph, 236, 1978.

17. Reshotko, E., "Boundary Layer Stability and Transition," Annual Rev. of Fluid Mech., Vo1. 8, 1976, pp. $311-350$.

18. Tani, I., "Three-Dimensional Aspects of Boundary Layer Transition," Proc. Indian Acad. Sci., Vol. 4, Part 2, August 1981, pp. 219-238.

19. "Laminar-Turbulent Transition," AGARD-CP224, May, 1977.

20. Junkhan, G. H. and Serovy, G. K., "Effects of FreeStream Turbulence and Pressure Gradient on FlatPlate Boundary Layer Velocity Profiles and on Heat Transfer," Trans. of ASME, J. of heat Transfer, May, 1967, pp. 169-176.

21. Simon, T. W. and Moffat, R. J., "Turbulent Boundary Layer Heat Transfer Experiments: A Separate Effects Study on a Convexly Curved Wall" J. of Heat Transfer, Vo1. 105, November 1983, pp. 835-840.

22. Bla1r, M. F., "Influence of Free-Stream Turbulence on Boundary Layer Transition in Favorable Pressure Gradients," Trans. of ASME, J. of Engr. for Power, Vol. 104, October 1982, pp. 743-750.

23. Blair, M. F., "Influence of Free-Stream Turbulence on Turbulent Boundary-Layer Heat Transfer and Mean Profile nevelooment, Part I -- Experimental Data," Trans. of ASME, J. of Heat Transfer, Vol. 105, February 1983, pp. 33-40. 
24. Perry, A. E., "Hot-Wire Anemometry," Claredon Press, Oxford, 1982 .

25. Kline, S. J. and McClintock, F. A., "Describing Uncertainties in Single-Sample Experiments," J. of Mech. Eng. Sc1., Vo1. 75, 1953, pp. 3-8.

26. Moffat, R. J., "Contributions to the Theory of Single-Sample Uncertalnty Analysis," J. of Fluids Engr., VoI. 104, 1982, pp. 250-260.

27. Wang, T. and Simon, T, W., "Using Uncertainty Analysis to Guide Test Program Development: A Case Study," Internal Report, Heat Transfer Lab., Dept. of Mech. Engr., University of Minnesota, January 1984 .

28. Wang, T., "An Experimental Investigation of Curvature and Free-Stream Turbulence Effects on Heat Transfer and Fluid Mechanics in Transitional Boundary Layers," Ph.D. Thesis, Dept. of Mech. Engr., University of Minnesota, December 1984.

29. Kays, W. M. and Crawford, M. E., Convect1ve Heat and Mass Transfer, McGraw-Hill, 2nd Ed., 1980.

30. Schilchting, H., Boundary Layer Theory, McGraw-Hill, NY, 7th Ed., 1979, Chap. XVI.

31. Kachanov, Yu. S, and Levchenko, V. Ya., "The Resonant Interaction of Disturbances at Laminar-turbu- lent Transition in a Boundary Layer," J. of Fluid Mech., Vo1. 138, 1984, pp. 209-247.

32. McDonald, H. and F1sh, R. W., "Practical Calculations of Transitional Boundary Layers," Int. J. Heat Mass Transfer, Vol. 16, 1973, pp. 1729-1744.

33. Spalding, D. B., "Contribution to the Theory of Heat Transfer Across a Turbulent Boundary Layer," Int. J. Heat Mass Transfer, Vol. 17, No. 7, July, 1964, pp. 743-761.

34. Simonich, J. C. and Bradshaw, P., "Effect of FreeStream Turbulence on Heat Transfer through a Turbulent Boundary Layer," J. of Heat Transfer, Trans. of ASME, Vol, 100, Nov. 1978, pp. 671-677.

35. Clauser, F. H., "The Turbulent Boundary Layer," Advances in Applied Mechanics, Vo1. IV, 1956, Academic Press, New York, pp. 1-51.

36. Klebanoff, P. S., "Characterist1cs of Turbulence in a Boundary Layer with Zero Pressure Gradient," NACA Report, 1247, 1955.

37. Buddhavarapu, J., "An Experimental Study of Trans1tional Boundary Layers on a Flat Plate". M. S. Thesis, Dept. of Mech. Engr., University of Minnesota, Sept. 1984. 